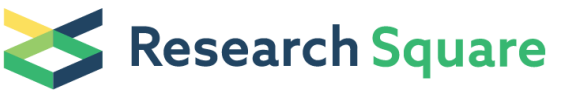

Preprints are preliminary reports that have not undergone peer review.

They should not be considered conclusive, used to inform clinical practice,

or referenced by the media as validated information.

\section{Early Overexpression of Pyruvate Dehydrogenase Kinase 4 can Affect Oxidate Stress After Subarachnoid Hemorrhage}

\section{xuan gao}

Nanjing Drum Tower Hospital: Nanjing University Medical School Affiliated Nanjing Drum Tower Hospital lingyun wu

Nanjing Drum Tower Hospital: Nanjing University Medical School Affiliated Nanjing Drum Tower Hospital yongyue gao

Nanjing Drum Tower Hospital: Nanjing University Medical School Affiliated Nanjing Drum Tower Hospital zheng peng

Nanjing Drum Tower Hospital: Nanjing University Medical School Affiliated Nanjing Drum Tower Hospital xunzhi liu

Nanjing Drum Tower Hospital: Nanjing University Medical School Affiliated Nanjing Drum Tower Hospital xiangxin chen

Nanjing Drum Tower Hospital: Nanjing University Medical School Affiliated Nanjing Drum Tower Hospital sen gao

Nanjing Drum Tower Hospital: Nanjing University Medical School Affiliated Nanjing Drum Tower Hospital huajie xu

Nanjing Drum Tower Hospital: Nanjing University Medical School Affiliated Nanjing Drum Tower Hospital qingrong zhang

Nanjing Drum Tower Hospital: Nanjing University Medical School Affiliated Nanjing Drum Tower Hospital chunhua hang

Nanjing Drum Tower Hospital: Nanjing University Medical School Affiliated Nanjing Drum Tower Hospital zong zhuang

Nanjing Drum Tower Hospital: Nanjing University Medical School Affiliated Nanjing Drum Tower Hospital Wei Li ( $D$ Iwxzlw@126.com)

Nanjing University Medical School https://orcid.org/0000-0002-9258-3500

\section{Research Article}

Keywords: PDK, PDH, pyruvate, oxidative stress, SAH, apoptosis

Posted Date: June 30th, 2021

DOI: https://doi.org/10.21203/rs.3.rs-655515/v1 
License: (a) (i) This work is licensed under a Creative Commons Attribution 4.0 International License. Read Full License 


\section{Abstract}

Pyruvate dehydrogenase (PDH), a key enzyme on the mitochondrial outer membrane, has been found to decrease activity notably in early brain injury (EBI) after subarachnoid hemorrhage (SAH). It has been demonstrated that PDH is associated with the production of reactive oxygen species (ROS) and apoptosis. Hence, in this study, we aimed to determine the cause of the decreased PDH activity and explore the potential role of PDH in EBI. We investigated the expression changes of PDH and pyruvate dehydrogenase kinase (PDK) in vivo and in vitro. Then, we explored the possible effects of PDH and ROS after SAH. The results showed that early overexpression of PDK4 promoted the phosphorylation of PDH, inhibited PDH activity and may play a protective role after SAH in vivo and in vitro. Finally, we investigated the levels of PDK4 and pyruvate, which accumulated due to decreased PDH activity, in the cerebrospinal fluid (CSF) of 34 patients with SAH. Statistical analysis revealed that PDK4 and pyruvate expression was elevated in the CSF of SAH patients compared with that of controls, and this high expression correlated with the degree of neurological impairment and long-term outcome. Taken together, the results show that PDK4 has the potential to serve as a new therapeutic target and biomarker for assisting in the diagnosis of SAH severity and prediction of recovery.

\section{Introduction}

Subarachnoid hemorrhage (SAH) is a central nervous system disease with high mortality and morbidity [10, $32,34]$. Early brain injury (EBI) is the most common cause of severe neurological impairment and unfavorable prognosis in SAH patients [5,20]. EBI occurs within $72 \mathrm{~h}$ after SAH and includes various mechanisms: blood-brain barrier disruption, inflammation, oxidative stress, cell death and mitochondrial dysfunction [24]. Although many treatments have been designed, their translation into clinical practice still fails. We need to make greater efforts to explore the pathology of EBI and find new therapeutic targets.

Pyruvate dehydrogenase (PDH), located in the outer mitochondrial membrane, is a key regulatory enzyme in energy metabolism. It catalyzes the conversion of pyruvate to acetyl-coenzyme A (acetyl-CoA) [12, 30, 31]. Pyruvate dehydrogenase kinase (PDK) is also located in the outer mitochondrial membrane and can negatively regulate PDH activity by phosphorylating one of its subunits. PDK has four known tissue-specific isozymes that share 70\% DNA sequences [29]. PDK1, the largest of the four isozymes, contains 436 amino acid residues. PDK2, PDK3 and PDK4 are composed of 407, 406 and 411 amino acid residues, respectively. Furthermore, various isozymes play different roles. PDK1 is expressed mostly in cardiomyocytes; PDK2 is expressed widely except in spleen and lung; PDK3 is expressed mainly in spermary; and PDK4 is mainly expressed in muscle and in brain, which consume a great amount of oxygen $[4,42]$. The effects of PDK and PDH on metabolism play an important role in many pathological processes. In a study of cancer, it was demonstrated that the overexpression of PDK1 results in a decrease in the activity of PDH, affects the metabolic state of cancer cells and promotes the growth, survival and invasion of cancer cells $[15,22,27]$. In addition, some studies have demonstrated that activated PDH promotes the production of ROS, induces mitochondrial outer membrane permeabilization (MOMP) and leads to apoptosis. In recent years, it has been demonstrated that pyruvate accumulates as a result of suppression of PDH activity and may scavenge ROS and protective cells $[3,18,45]$. 
After the establishment of the SAH model, it was found that the activity of PDH decreases obviously, oxidative metabolism is disrupted and pyruvate levels are increased [39-41]. However, the reason for and likely consequences of the PDH activity decrease remain unclear. Thus, we assessed the expression of PDK and $\mathrm{PDH}$ in vivo and in vitro after SAH by western blotting (WB) and real-time quantitative polymerase chain reaction (qPCR). The levels of PDK and pyruvate in the CSF of patients with SAH were assessed, and we analyzed whether PDK or pyruvate can be a predictor of severe injuries and/or unfavorable outcomes.

\section{Method And Materials}

\section{Rat and model}

75 healthy adult male Sprague-Dawley rats weighing 230-320g were purchased from Animal Core Facility of Nanjing Medical University. All experiments were carried out under the Guide for the Care and Use of Laboratory Animals published by NIH and approved by the Experimental Animal Ethics Committee of Nanjing Drum Tower, approved number: 2020AE02015. All animal studies are reported in compliance with the ARRIVE guidelines $[13,23]$.

The endovascular perforation SAH model was performed as previously described $[16,17,35]$. The endovascular perforation surgery was performed by the same experimenter (X.G.). Briefly, rats were anaesthetized by isoflurane inhalation (RWD Life Science, Shenzhen) firstly. After sharpness and blunt separation, a marked 6 - 0 filament was inserted to the middle cerebral artery (MCA) through the internal carotid artery (ICA). We punctured the bifurcation of the anterior and middle cerebral arteries in SAH group. In sham group, the filament was pulled out without puncturing the artery.

The neurological score was blindly evaluated by two independent observers using a Modified Garcia scale score $24 \mathrm{~h}$ post-SAH $[21,35]$. Rats with a Modified Garcia scale score $\leq 6$ or $\geq 15$ were excluded to prevent the interference of dying models and failure SAH models.

\section{Primary neuron culture}

For neuron culture, the cortex was obtained from rats at embryonic day $13-15$ as we previously reported [16, 17, 35]. In brief, after removing leptomeninges, cerebral cortex was digested with Trypsin. Then we used fetal bovine serum to stop the digestion and repeated triturated the neuron suspension. After filtration and centrifugation, the remaining neurons were seeded in poly-D-lysine-coated plates with neurobasal medium and incubated at $37^{\circ} \mathrm{C}$ and $5 \% \mathrm{CO} 2$. The medium contained $0.5 \mathrm{mM}$ GlutaMax (Gibco Company, USA) and 2\% B27 supplement (Gibco Company, USA). We would replace the medium at $4 \mathrm{~h} \otimes 3 \mathrm{~d} \otimes 5 \mathrm{~d}$ and $7 \mathrm{~d}$ following seeding. For the in vitro SAH model, neurons were treated with hemoglobin ( $\mathrm{Hb}$, Sigma, USA) at a concentration of $25 \mathrm{uM}$ for $24 \mathrm{~h}$. Primary neurons were randomly assigned to different groups.

\section{Patient population}

Patients with SAH were recruited from the Department of Neurosurgery of the Nanjing Drum Tower Hospital between April 2020 and April 2021. A diagnosis of severe SAH required a positive cranial CT scan and bloody cerebrospinal fluid. For all SAH subjects, the inclusion criteria were: 
(1) patient age between 16 and 70 years,

(2) signed consent from the subject or next of kin,

(3) a Hunt-Hess grade of 1 or 2.

The exclusion criteria were:

(1) failure to meet the inclusion criteria or unfit for the experiment as determined by the responsible doctor,

(2) presence of severe cardiac insufficiency, renal dysfunction, diabetes or other systemic diseases,

(3) a history of traumatic brain injury, severe cerebral edema or hydrocephaly.

As a control group, knee arthritis subjects who needed surgery were recruited. For control subjects, the inclusion criteria were:

(1) patient age between 16 and 70 years,

(2) no current or pre-existing brain injuries, neurological diseases, or bleeding disorders, and subjects who needed surgery for knee arthritis,

(3) signed consent from the subject or next of kin.

Ultimately, 34 patients with SAH and 6 controls were included. Patient demographics are shown in Table 1. The study was approved by the Ethics Committee of Drum Tower Hospital (No. 2020-041-01) and registered in the Chinese Clinical Trial Registry (ChiCTR2100042986). Written informed consent was obtained from each participant. 
Table 1

Summary of demographic data in patients with SAH

\begin{tabular}{|c|c|c|c|c|c|c|c|c|c|}
\hline $\begin{array}{l}\text { Case } \\
\text { No. }\end{array}$ & $\begin{array}{l}\text { Age } \\
\text { (years) }\end{array}$ & Gender & $\begin{array}{l}\text { Hyper- } \\
\text { tension }\end{array}$ & Aneurysm & $\begin{array}{l}\text { Days after } \\
\text { hemorrhage } \\
\text { (d) }\end{array}$ & $\begin{array}{l}\text { Initial } \\
\text { GCS }\end{array}$ & $\begin{array}{l}\text { Initial } \\
\text { Hunt- } \\
\text { Hess }\end{array}$ & $\begin{array}{l}\text { Initial } \\
\text { GOS }\end{array}$ & $\begin{array}{l}\text { GOS } \\
\text { (after } 3 \\
\text { months) }\end{array}$ \\
\hline 1 & 63 & $\mathrm{~F}$ & 1 & 1 & 1 & 15 & 3 & 5 & 5 \\
\hline 2 & 72 & $\mathrm{~F}$ & 1 & 1 & 1 & 15 & 1 & 5 & 5 \\
\hline 3 & 54 & $M$ & 0 & 1 & 1 & 3 & 4 & 1 & 1 \\
\hline 4 & 75 & $F$ & 0 & 1 & 1 & 8 & 4 & 3 & 3 \\
\hline 5 & 65 & $F$ & 1 & 1 & 1 & 15 & 2 & 4 & 5 \\
\hline 6 & 69 & $\mathrm{~F}$ & 1 & 0 & 1 & 15 & 2 & 5 & 5 \\
\hline 7 & 69 & $F$ & 0 & 1 & 1 & 15 & 3 & 5 & 5 \\
\hline 8 & 48 & M & 0 & 1 & 1 & 14 & 3 & 3 & 4 \\
\hline 9 & 64 & $M$ & 1 & 1 & 2 & 14 & 3 & 4 & 5 \\
\hline 10 & 76 & M & 0 & 1 & 2 & 7 & 4 & 3 & 5 \\
\hline 11 & 40 & $F$ & 1 & 1 & 2 & 15 & 3 & 3 & 5 \\
\hline 12 & 50 & $F$ & 0 & 1 & 2 & 9 & 4 & 3 & 5 \\
\hline 13 & 62 & $\mathrm{~F}$ & 1 & 1 & 2 & 5 & 4 & 1 & 1 \\
\hline 14 & 49 & $F$ & 0 & 1 & 2 & 12 & 3 & 4 & 5 \\
\hline 15 & 56 & $F$ & 1 & 0 & 2 & 15 & 1 & 4 & 5 \\
\hline 16 & 66 & $\mathrm{~F}$ & 1 & 1 & 2 & 5 & 3 & 5 & 5 \\
\hline 17 & 63 & $M$ & 0 & 0 & 2 & 14 & 2 & 5 & 5 \\
\hline 18 & 55 & $M$ & 1 & 1 & 2 & 15 & 1 & 5 & 5 \\
\hline 19 & 45 & $M$ & 1 & 1 & 2 & 15 & 3 & 5 & 5 \\
\hline 20 & 63 & $M$ & 1 & 0 & 2 & 15 & 2 & 5 & 5 \\
\hline 21 & 73 & $F$ & 1 & 1 & 2 & 14 & 3 & 3 & 3 \\
\hline 22 & 45 & $F$ & 1 & 1 & 2 & 15 & 2 & 5 & 5 \\
\hline 23 & 47 & $F$ & 0 & 1 & 3 & 15 & 2 & 4 & 4 \\
\hline 24 & 49 & $M$ & 0 & 1 & 3 & 15 & 2 & 4 & 5 \\
\hline 25 & 53 & $M$ & 0 & 0 & 3 & 15 & 2 & 4 & 5 \\
\hline 26 & 54 & $F$ & 0 & 1 & 3 & 15 & 2 & 4 & 5 \\
\hline
\end{tabular}




\begin{tabular}{|llllllllll|}
\hline $\begin{array}{l}\text { Case } \\
\text { No. }\end{array}$ & $\begin{array}{l}\text { Age } \\
\text { (years) }\end{array}$ & Gender & $\begin{array}{l}\text { Hyper- } \\
\text { tension }\end{array}$ & Aneurysm & $\begin{array}{l}\text { Days after } \\
\text { hemorrhage } \\
\text { (d) }\end{array}$ & $\begin{array}{l}\text { Initial } \\
\text { GCS }\end{array}$ & $\begin{array}{l}\text { Initial } \\
\text { Hunt- } \\
\text { Hess }\end{array}$ & $\begin{array}{l}\text { Initial } \\
\text { GOS }\end{array}$ & $\begin{array}{l}\text { GoS } \\
\text { (after 3 } \\
\text { months) }\end{array}$ \\
\hline 27 & 72 & F & 0 & 1 & 3 & 14 & 1 & 4 & 5 \\
\hline 28 & 55 & M & 0 & 1 & 3 & 15 & 2 & 4 & 5 \\
\hline 29 & 63 & F & 1 & 1 & 3 & 15 & 3 & 4 & 5 \\
\hline 30 & 68 & M & 1 & 1 & 3 & 14 & 3 & 4 & 5 \\
\hline 31 & 57 & F & 1 & 1 & 3 & 14 & 2 & 4 & 5 \\
\hline 32 & 65 & F & 1 & 1 & 3 & 14 & 2 & 3 & 5 \\
\hline 33 & 57 & F & 1 & 1 & 3 & 15 & 1 & 4 & 5 \\
\hline 34 & 52 & M & 1 & 1 & 3 & 15 & 1 & 5 & 5 \\
\hline
\end{tabular}

$\mathrm{d}=$ days; GCS = Glasgow Coma Scale; GOS = Glasgow outcome scale

lines of Hypertension and Aneurysm: $0=$ No; $1=$ yes

$\mathrm{F}=$ female; $\mathrm{M}=$ male

\section{Sample collection}

Cerebrospinal fluid (CSF) samples were collected within $72 \mathrm{~h}$ after SAH following the consensus protocol for the standardization of cerebrospinal fluid

collection [37]. The posterior cerebrospinal fluid was retained as samples and centrifuged at $2000 \mathrm{~g}$ for 15 minutes at $4^{\circ} \mathrm{C}$ to pellet cellular bodies and debris. All samples were stored at $-80^{\circ} \mathrm{C}$.

\section{Experimental design}

The main experimental protocols are described as follows (Fig. 1):

\section{Experiment 1}

To examine the expression variation of PDKs and PDH in rat brain after SAH, a total of 50 rats were randomly assigned to six groups: sham $(n=5), 6$ h post-SAH $(n=9), 24$ h post-SAH $(n=9), 2$ days post-SAH $(n=9), 3$ days post-SAH $(n=9)$ and 7 days post-SAH $(n=9)$. Five rats from each group were sacrificed randomly for WB and qPCR. In stage 2, 15 rats were randomly allocated into two groups: the sham group (n $=6)$ and the SAH group (2 days) $(n=9)$. Six rats from each group were selected randomly for immunofluorescence staining.

\section{Experiment 2}


To examine the expression variation of PDKs and PDH in cultured neurons after $\mathrm{Hb}$ stimulation, $\mathrm{Hb}$ from bovine erythrocytes (Sigma, USA) was dissolved in complete culture medium at a concentration of 25 $\mu \mathrm{mol} / \mathrm{L}$. Cultured neurons were randomly assigned to six groups (the control group and $\mathrm{Hb}$ groups $(1 \mathrm{~h}, 3 \mathrm{~h}$, $6 \mathrm{~h}, 12 \mathrm{~h}, 24 \mathrm{~h})(\mathrm{n}=5 \mathrm{each})$ ) for WB and five groups (the control group and Hb groups ( $1 \mathrm{~h}, 4 \mathrm{~h}, 12 \mathrm{~h}, 24 \mathrm{~h}$ ) (n $=5$ each) $)$ for qPCR. Finally, the control group and $12 \mathrm{~h}$ post-Hb group were used for immunofluorescence staining and TUNEL staining.

\section{Experiment 3}

To examine the levels of PDK4 and pyruvate in the CSF of patients with SAH, CSF samples were collected from 34 SAH patients and 6 controls for ELISA.

\section{Western blot}

The brains were removed and the basal cortex tissues were collected and washed. Neurons cultured in sixwell plated were washed with phosphate-buffered saline (PBS). Cortex tissues and neurons were lysed with RIPA buffer (Thermo Scientific, USA) with protease inhibitor (Roche, Switzerland) and phosphatase inhibitor (Thermo Fisher Scientific). A bicinchoninic acid protein assay kit (Beyotime, China) was used to quantified the amounts of protein. The same amount of protein was resolved by SDA-PAGE (EpiZyme Scientific) and transferred to polyvinylidene difluoride membranes (Millipore, USA). We used 2\% BSA to block the membranes for $2 \mathrm{~h}$ at room temperature. After incubation with diluted primary antibody overnight at $4{ }^{\circ} \mathrm{C}$, the membranes were washed 3 times for 10 min with PBS and Tween 20. The antibodies were as follows: anti-PDK1 (1:1000, 3820, Cell Signaling Technology), anti-PDK2 (1:1000, 68164, Abcam), anti-PDK3 (1:1000, 154549, Abcam), anti-PDK4 (1:1000, 89295, Abcam), anti-PDH (1:1000, 3205, Cell Signaling Technology), anti- phospho-PDH(S293) (1:1000, 177461, Abcam), anti-ASK1 (1:1000, 45178, Abcam), anti-phospho-ASK1 (Thr845) (1:1000, 3765, Cell Signaling Technology), anti-P38 (1:1000, 9212, Cell Signaling Technology), antiphospho-P38 (Thr180/Tyr182) (1:1000, 9211, Cell Signaling Technology), anti-BAX (1:1000, 2772, Cell Signaling Technology), anti- BCL2 (1:1000, 32124, Abcam), anti-caspase3 (1:1000, 9662, Cell Signaling Technology), anti-cleaved-caspase3 (Asp175) (1:1000, 9664, Cell Signaling Technology) and anti-GAPDH (1:5000, AP0066, Bioworld). The membranes were incubated with horseradish peroxidase (HRP)-conjugated secondary antibody (Bioworld) for $1 \mathrm{~h}$ at room temperature. Finally, the bands were detected by Immobilon Western Chemiluminescent HRP Substrate (Millipore Sigma, Burlington, MA, USA). Images were analyzed with ImageJ software (National Institutes of Health, Bethesda, MD, USA) and normalized against GAPDH.

\section{Real-time PCR}

The total RNA of basal cortex tissues and neurons was extracted by TRIzol reagent (Invitrogen, USA) according to the manufacturer's instructions. cDNA was reverse transcribed from mRNA with a reverse transcription mix (Vazyme, Nanjing) after removal of genomic DNA. qPCR was performed using a PCR system (Applied Biosystems, United States) with a SYBER Green mix (Roche, Switzerland). The primers used in qPCR are listed in Table 2. The results were analyzed with the $2-\triangle \Delta C$ t method and normalized against GAPDH too. 
Table 2

polymerase chain reaction (PCR) primer sequences

\begin{tabular}{|c|c|c|}
\hline Target gene & Forward (5' to $\left.3^{\prime}\right)$ & Reverse ( $5^{\prime}$ to $\left.3^{\prime}\right)$ \\
\hline PDK1 & GTTCAGTACTTTTTGGATCGGTTC & TCGACTACATCACAGTTTGGATTT \\
\hline PDK2 & TGGACCGCTTCTACCTCAG & TCTTTCACCACATCAGACACG \\
\hline PDK3 & TGACCTAGGTGGTGGAGTCCCA & ACCAAATCCAGCCAAGGGAGCA \\
\hline PDK4 & GAACACCCCTTCCGTCCAGCT & TGTGCCATCGTAGGGACCACA \\
\hline BAX & GACACCTGAGCTGACCTTGG & GAGGAAGTCCAGTGTCCAGC \\
\hline $\mathrm{BCL} 2$ & TATGATAACCGGGAGATCGTGATC & GTGCAGATGCCGGTTCAGGTACTC \\
\hline GAPDH & TGTGAAGCTCATTTCCTGGTA & TTACTCCTTGGAGGCCATGT \\
\hline
\end{tabular}

\section{Immunofluorescence staining}

Brain tissue was postfixed in 4\% paraformaldehyde, dehydrated with sucrose solution and sliced to 10 um. Cultured neurons were fixed with $4 \%$ paraformaldehyde. Then they were permeabilized with $0.3 \%$ Triton X100, and blocked with immunostaining blocking solution (Epizyme, Shanghai). After incubation with diluted primary antibody overnight at $4{ }^{\circ} \mathrm{C}$, the membranes were washed 3 times for 10 min with PBS and Tween 20. The antibodies were as follows: anti-PDK4 (1:200, 89295, Abcam), anti-NeuN (1:200, 26975-1-AP, Proteintech), anti-Iba1(1:200, 5076, Abcam), anti-GFAP(1:200, 4648, Abcam). The next day, they were incubated with corresponding secondary antibodies: anti-rabbit Alex Fluor 488-conjugated secondary antibody (1:200, A11008, Invitrogen), anti-rabbit Alexa Fluor 594-conjugated secondary antibody (1:200, A32754, Invitrogen), anti-mice Alexa Fluor 594-conjugated secondary antibody (1:200, A32740, Invitrogen), anti-mice Alexa Fluor 488-conjugated secondary antibody (1:200, A32723, Invitrogen). Immunofluorescence images were captured using the microscope (ZEISS, HB050, Germany) and analyzed with ImageJ.

\section{Enzyme Linked Immunosorbent Assay}

The levels of PDK4 were determined by an ELISA kit (abx252933, Abbexa) according to the manufacturer's instruction. In brief, CSF and standard samples were loaded in to the 96-well plate incubated with PDK4 antibody. After incubation of detection reagent $A$ and $B$, the TMB substrate and stop solution were added to every well. Finally, the results were detected at OD $450 \mathrm{~nm}$ in a microplate reader (Tecan, Switzerland). The levels of PDK4 were calculated according to the standard curve.

\section{Pyruvate assay}

The levels of pyruvate were detected by a pyruvate assay kit (\#K609-100, Biovision, USA) according to the manufacturer's instructions. Briefly, after brain tissue and cultured neurons were extracted, samples were homogenized. Subsequently, the supernatant was collected after centrifugation at $10000 \mathrm{xg}$ for $10 \mathrm{~min}$ at $4^{\circ} \mathrm{C}$. Finally, the fluorescence was detected at an Ex/Em of 435/590 $\mathrm{nm}$ in a microplate reader (Tecan, Switzerland). A preliminary experiment in which color (OD $570 \mathrm{~nm}$ ) was used to calculate the results was 
essential to determine the appropriate loading volume. The pyruvate contents were calculated according to the manufacturer's instructions.

\section{Terminal deoxynucleotidyl transferase-mediated dUTP nick end labeling}

TUNEL staining was performed on frozen brain sections and cultured neurons with a TUNEL detection kit (Beyotime, China) according to the manufacturer's instructions. After incubation with a primary antibody against NeuN (1:200, 26975-1-AP, Proteintech) at $4{ }^{\circ} \mathrm{C}$ overnight, the TUNEL reaction mixture were loaded into every section for $1 \mathrm{~h}$ at $37^{\circ} \mathrm{C}$. The images were captured using the microscope (ZEISS, HB050, Germany) and analyzed with ImageJ.

\section{Modified Garcia scale}

We used the Modified Garcia scale to assess the functional defects at 1 days post-SAH by two observers who were blind to groups $[35,43]$. It contains 6 tests covering spontaneous activity and movement of the four limbs, forepaw outstretching, climbing, body proprioception, and response to whisker stimulation.

\section{Statistical analysis}

Glasgow Coma Scale (GCS) scores 1-3 days after SAH were categorized as severe (GCS score $<12$ ) or mild (GCS score 12-15) injury for each subject.

Hunt-Hess Scale scores obtained 1-3 days after SAH were used to assess neurological impairment. The subjects were divided into two groups: those with Hunt-Hess scores of 1-2 and those with Hunt-Hess scores of $3-4$.

Glasgow Outcome Scale (GOS) scores at 3 months were compared with those at 1-3 days after SAH to sort subjects into an improved group and an unchanged group for ease of presentation and interpretation of results. Subjects whose initial GOS scores and GOS scores after 3 months were both 5 were excluded.

Statistical analysis was performed using Prism 8.01 (GraphPad Software, USA). Two -tailed unpaired Student's t-test was used to compare two experimental groups after normality and lognormality tests were satisfied. One-way ANOVA followed by Tukey's test was performed to assess differences between more than two groups. Two-way ANOVA was used to assess the interaction effects of treatments and time courses. $P$ $<0.05$ was considered statistically significant. All data are expressed as the means \pm SD.

\section{Results}

\section{Mortality and exclusion}

No rats died in the sham group, and the overall mortality of the SAH group was $18.5 \%(10 / 54)$. According to the modified Garcia scores at 1 day post-SAH, a total of 13 rats were excluded from this study (Table 3 ). 
Table 3

Mortality and exclusion

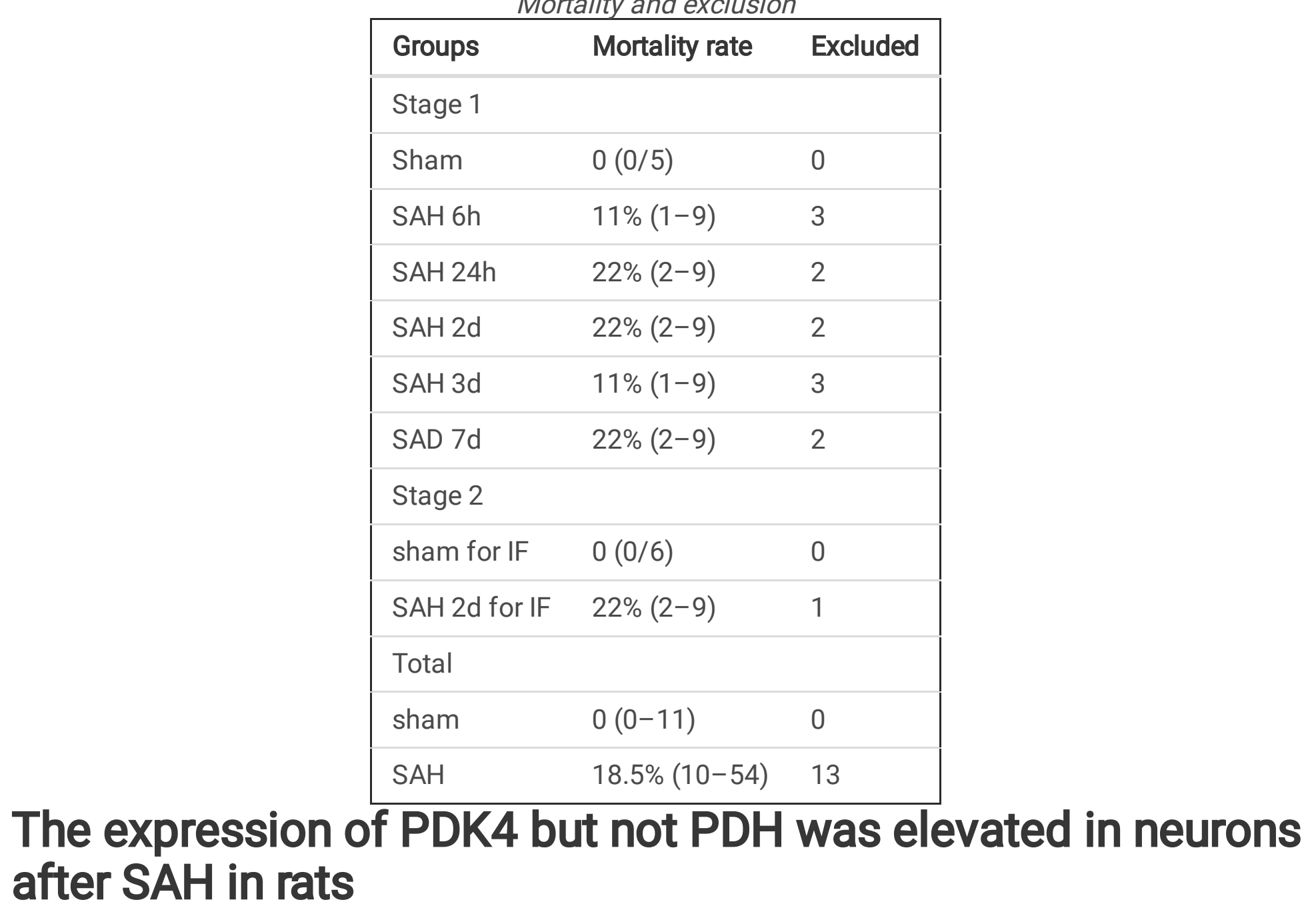

To determine the expression of PDKs and PDH at different time points after SAH, rat brain tissues were obtained and analyzed by western blot and qPCR (Fig. 2D-G). PDK4 was significantly elevated $24 \mathrm{~h}$ after $\mathrm{SAH}$ and peaked at 2 days. There were no significant differences in the expression of PDK1, PDK2, or PDK3 after SAH. Consistent with PDK4, p-PDH reached peak expression at 2 and 3 days after SAH, while the expression of PDH showed little change (Fig. 2D, E). Immunofluorescence staining showed that PDK4 was highly expressed in neurons (Fig. 2B), expressed at a low level in microglia (Fig. 2A), and barely expressed in astrocytes (Fig. 2C). The results verified that PDK4 was overexpressed mainly in neurons after SAH.

\section{Neuronal apoptosis participated in the pathology of EBI in vivo}

To better understand the effect of overexpressed PDK4 after SAH, apoptosis and related agents were evaluated (Fig. 3). The protein levels of p-ASK1 and p-p38 were significantly increased, and cleaved caspase3 accumulated after SAH (Fig. 3A - D). In addition, the levels of Bax and Bcl-2 were upregulated at both the protein and mRNA levels 2 days after SAH (Fig. 3E). Finally, TUNEL staining confirmed that neuronal apoptosis was significantly aggravated after SAH (Fig. 3F). These results reflected that overexpressed PDK4 may be related to neuronal apoptosis after SAH. 


\section{$\mathrm{Hb}$ exposure also induced the overexpression of PDK4 in neurons in vitro}

We constructed an in vitro SAH model by $\mathrm{Hb}$ stimulation and performed western blotting and qPCR to assess the protein and mRNA expression of related genes. As shown in Fig. 4C and D, the levels of PDK4 protein and mRNA were increased after $\mathrm{Hb}$ exposure and peaked at $3 \mathrm{~h}$. The levels of PDK1, PDK2 and PDK3 were not different after $\mathrm{Hb}$ stimulation. Similar to the change in rats after SAH, PDH expression was not significantly altered after $\mathrm{Hb}$ stimulation, but $\mathrm{p}-\mathrm{PDH}$ expression reached a peak at $1 \mathrm{~h}$ in neurons after $\mathrm{Hb}$ stimulation (Fig. 4A, B). Immunofluorescence staining also showed that PDK4 was overexpressed in neurons after $\mathrm{Hb}$ stimulation (Fig. 4E).

\section{$\mathrm{Hb}$ exposure activated the pathway of neuronal apoptosis in vitro}

To verify that the pathological processes of the SAH in vitro model were consistent with those of the SAH in vivo model, apoptosis and related agents were assessed and found to be elevated in vitro (Fig. 4). The levels of p-ASK1, p-p38 and cleaved caspase were obviously increased in neurons after Hb stimulation (Fig. 5A D). In addition, the protein and mRNA levels of Bax and Bcl-2 increased and peaked at $3 \mathrm{~h}$ in neurons after $\mathrm{Hb}$ stimulation (Fig. 5E). TUNEL staining also reflected that neuronal apoptosis significantly increased after $\mathrm{Hb}$ stimulation (Fig. 5F). These results indicated that neuronal apoptosis was involved in the pathological processes of the in vivo an in vitro SAH models.

\section{The expression of PDK4 was elevated in the CSF of SAH patients}

As shown in Fig. 6, the levels of PDK4 and pyruvate were significantly elevated in the CSF of SAH patients after $1-3$ days compared with controls (both $p<0.0001$ ). There was no difference in PDK4 and pyruvate levels each day after SAH. Two maximum values of PDK4 at 3 days in the SAH group were removed.

Different levels of PDK4 and pyruvate were associated with the neurological function scores of SAH patients

To determine whether the levels of PDK4 and pyruvate correlated with neurological injury, we grouped study participants by injury category: GCS scores < 12, severe injury; GCS scores 12-15, mild injury; Hunt-Hess scores 1-2; and Hunt-Hess scores 3-4. We detected significantly higher levels of PDK4 (Fig. 7A, C) and pyruvate (Fig. 7B, D) in the CSF of SAH patients with mild injury ( $p=0.0176$ and $p=0.0414)$ and Hunt-Hess scores $1-2(p=0.0073$ and $p=0.0255)$. Two maximum values of PDK4 were removed from both the mild injury group and the Hunt-Hess scores 1-2 group.

\section{Different levels of PDK4 and pyruvate were related to long- term outcomes of SAH patients}


To explore the correlation of PDK4 and pyruvate levels and long-term outcomes of SAH patients, the difference in GOS scores at 3 months compared with 1-3 days after SAH was used to assess the long-term outcome of SAH patients. Subjects whose initial GOS scores and GOS scores after 3 months were both 5 were excluded. As shown in Fig. 8, the levels of PDK4 and pyruvate in the improved group were significantly higher than those in the unchanged group $(p=0.0027$ and $p=0.0011)$. Two maximum values of PDK4 in the improved group were removed.

\section{Discussion}

In this study, we demonstrated that overexpression of PDK4 promoted the phosphorylation of PDH and inhibited PDH activity after SAH. The expression of PDH was unchanged, but the apoptosis signalregulating kinase 1 (ASK1)/p38 pathway was activated after SAH, resulting in apoptosis. Previous studies suggested that activated PDH promotes the production of reactive oxygen species (ROS) [3]. ROS are highly reactive chemical molecules including peroxides, superoxide, hydroxyl radicals, and singlet oxygen [9]. Under normal conditions, ROS are present at low and stationary levels in cells and can participate in cell signaling and homeostasis $[7,14]$. However, ROS accumulate after pathological stimulation and cause irreversible damage to DNA. SAH damages the balance between ROS production and disposal and results in significant damage to cell structures during EBI. Therefore, early overexpression of PDK4 may protect cells from damage caused by ROS.

In our past research, we reported that the ROS-ASK1-p38 pathway promotes apoptosis after SAH [19, 44]. ASK1, known as mitogen-activated protein kinase 5 (MAPK5), is a member of the MAP kinase family and activates c-Jun N-terminal kinase (JNK) and p38 mitogen-activated protein kinases in response to stresses such as oxidative stress, endoplasmic reticulum stress and calcium influx. In a variety of studies, ASK1 has been found to play an important role $[8,26]$. p38 is also a member of the class of MAP kinases and is responsive to stress stimuli $[6,33]$. Under pathological stresses, the activity of p38 is stimulated, and the activity of the transcription factor NF-KB is high. Dysregulation of p38 and NF-KB can result in apoptosis, autophagy and inflammation $[2,38]$. Caspase3 plays a central role in apoptosis, and we found that activated caspase3 was significantly increased after SAH in vivo and in vitro [1]. Similarly, the apoptosis promotor Bax and inhibitor Bcl2 were upregulated by pathological stress after SAH in vivo and in vitro. Their interaction determines whether apoptosis occurs $[25,28]$. The early overexpression of PDK4 after SAH inhibited the activity of PDH, promoted the efficient elimination of ROS and influenced the activity of the ASK1/p38 pathway, caspase3, Bax and Bcl2. Therefore, we hypothesized that PDK4 could protect cells, lessen neurofunctional injuries and function as a biomarker of outcome prediction after SAH.

We detected the levels of PDK4 and pyruvate in the CSF of SAH patients and controls, and the results showed that the levels of PDK4 and pyruvate were significantly elevated in the CSF of SAH patients compared with controls. Pyruvate was the reaction substrate of PDH and represented the activity of PDH. In some studies, the accumulation of pyruvate can protect cells from ROS damage [45]. GCS scores and HuntHess Scale scores 1-3 days after SAH were used to assess SAH severity, and GOS scores at 3 months compared with 1-3 days after SAH were used to assess the long-term outcome of SAH patients $[11,36]$. After analyzing PDK4 and pyruvate levels in the CSF of SAH patients, we found that patients with mild injury 
had higher levels of PDK4 and pyruvate in CSF and that there was a significant correlation between the levels of PDK4 and pyruvate in CSF and the long-term outcome of SAH patients.

To the best of our knowledge, this is the first report to demonstrate that early overexpression of PDK4 inhibited the activity of PDH and may play a protective role after SAH. Furthermore, we found that PDK4 and pyruvate were acutely elevated in the CSF of SAH patients compared with controls, and their high expression correlated with the degree of neurological impairment and long-term outcome. This is clinically meaningful and could function as a new therapeutic target or biomarker predicting initial injury to the brain and recovery potential. However, several limitations of this study should be addressed. The corresponding mechanisms should be explored further, and we plan to work toward this goal as the next step in our research. In addition, the number of subjects was relatively small, and thus we will continue to recruit patients for more reliable conclusions. As described above, we explored the expression variation and function of PDK4 in animal, cell and clinical experiments. These results showed that PDK4 is worth further exploration and has potential value for clinical transformation, serving as a new therapeutic target and biomarker.

\section{Conclusion}

Early overexpression of PDK4 promoted the phosphorylation of PDH and inhibited PDH activity after SAH. PDK4 has the potential to serve as a new therapeutic target and biomarker for use in the diagnosis of SAH severity and the prediction of recovery.

\section{Abbreviations}

acetyl-CoA: acetyl-coenzyme A; ASK1: apoptosis signal-regulating kinase 1; CSF: cerebrospinal fluid; GAPDH: glyceraldehyde 3-phosphate dehydrogenase; GCS: Glasgow Coma Scale; GFAP: glial fibrillary acidic protein; GOS: Glasgow outcome scale; EBI: early brain injury; Hb: hemoglobin; HRP: horseradish peroxidase; ICA: internal carotid artery; Iba1: ionized calcium binding adaptor molecule 1; JNK: Jun N-terminal kinase; MAPK5: mitogen-activated protein kinase 5; MCA: middle cerebral artery; MOMP: mitochondrial outer membrane permeabilization; NeuN: neuronal nuclei; PBS: phosphate-buffered saline; PDH: pyruvate dehydrogenase; PDK: pyruvate dehydrogenase kinase; PPAR: peroxisome proliferators-activated receptor; qPCR: real-time quantitative polymerase chain reaction; ROS: reactive oxygen species; SAH: subarachnoid hemorrhage; WB: western blotting;

\section{Declarations}

\section{Author contributions:}

X.G. performed the studies and wrote the manuscript; S.G. and X-X.C. participated in creating the experimental animal model; Y-Y.G. and H-J.X. participated in primary neuron culture. X.G. and L-Y.W. contributed to the Western blotting; Z.P., X-Z.L. and Q-R.Z. contributed to the collection of human cerebrospinal fluid; C-H.H., Z.Z. and W.L. contributed to the design and analysis of the study and revised the manuscript; and all authors analyzed the results and approved the final version of the manuscript. 


\section{Funding:}

This work was supported by National Natural Science Foundation of China (NSFC)

(No.81801166 for L.Y. Wu, NO. 81971127 for Z. Zhuang and NO. 81971122 for C.H. Hang), Nature Science Foundation of Jiangsu Province, China (BK20201113 for W. Li), Key Project of Medical Science and Technology Development Foundation, Nanjing Department of Health (NO. JQX18001 for W. Li) and the Fundamental Research Funds for the Central Universities (NO. 0214-14380482 for W. Li, No. 14380478 for L.Y. Wu).

\section{Data Availability:}

The datasets supporting the conclusions of this article are included within the article.

\section{Acknowledgements:}

\section{Conflict of Interest:}

The authors declare that they have no conflict of interest.

\section{Compliance with Ethical Standards:}

The study involving animals was approved by the Experimental Animal Ethics Committee of Nanjing Drum Tower (2020AE02015), the study involving human participants was approved by the Ethics Committee of Drum Tower Hospital (No. 2020-041-01) and registered in the Chinese Clinical Trial Registry (ChiCTR2100042986).

\section{Consent for Participate:}

Not applicable.

\section{Consent for Publication:}

Not applicable.

\section{References}

1. Yagi K, Lidington D, Wan H, Fares JC, Meissner A, Sumiyoshi M, Ai J, Foltz WD, Nedospasov SA, Offermanns S, Nagahiro S, Macdonald RL, Bolz SS (2015) Therapeutically Targeting Tumor Necrosis Factor-alpha/Sphingosine-1-Phosphate Signaling Corrects Myogenic Reactivity in Subarachnoid Hemorrhage. Stroke 46(8):2260-2270. https://doi:10.1161/STROKEAHA.114.006365

2. Hop JW, Rinkel GJ, Algra A, van Gijn J (1997) Case-fatality rates and functional outcome after subarachnoid hemorrhage: a systematic review. Stroke 28(3):660-664. doi 10.1161/01.str.28.3.660.

3. Zhang XS, Lu Y, Li W, Tao T, Peng L, Wang WH, Gao S, Liu C, Zhuang Z, Xia DY, Hang CH, Li W (2021) Astaxanthin ameliorates oxidative stress and neuronal apoptosis via SIRT1/NRF2/Prx2/ASK1/p38 
after traumatic brain injury in mice. Br J Pharmacol 178(5):1114-1132. https://doi:10.1111/bph.15346

4. Cahill J, Zhang JH (2009) Subarachnoid hemorrhage: is it time for a new direction? Stroke 40(3 Suppl):S86-S87. doi:10.1161/STROKEAHA.108.533315

5. Miller BA, Turan N, Chau M, Pradilla G (2014) Inflammation, vasospasm, and brain injury after subarachnoid hemorrhage. Biomed Res Int 2014:384342. https://doi:10.1155/2014/384342

6. Pierrat B, Simonen M, Cueto M, Mestan J, Ferrigno P, Heim J (2001) SH3GLB, a new endophilin-related protein family featuring an SH3 domain. Genomics 71(2):222-234.

https://doi:10.1006/geno.2000.6378

7. Vlahopoulos SA (2017) Aberrant control of NF-kappaB in cancer permits transcriptional and phenotypic plasticity, to curtail dependence on host tissue: molecular mode. Cancer Biol Med 14(3):254-270. https://doi:10.20892/j.issn.2095-3941.2017.0029

8. Kark R, Rodriguez-Budelli M, Blass J (1978) Evidence for a primary defect of lipoamide dehydrogenase in Friedreich's ataxia. Advances in neurology 21:163-180

9. Teunissen C, Petzold A, Bennett J, Berven F, Brundin L, Comabella M, Franciotta D, Frederiksen J, Fleming J, Furlan R, Hintzen R, Hughes S, Johnson M, Krasulova E, Kuhle J, Magnone M, Rajda C, Rejdak K, Schmidt H, van Pesch V, Waubant E, Wolf C, Giovannoni G, Hemmer B, Tumani H, DeisenhammerF (2009) A consensus protocol for the standardization of cerebrospinal fluid collection and biobanking. Neurology 73(22):1914-1922. doi:10.1212/WNL.0b013e3181c47cc2 https://

10. Teasdale G, Jennett B (1974) Assessment of coma and impaired consciousness. A practical scale. Lancet 2(7872):81-84. https://doi:10.1016/s0140-6736(74)91639-0

11. Bowker-Kinley M, Davis W, Wu P, Harris R, Popov K (1998) Evidence for existence of tissue-specific regulation of the mammalian pyruvate dehydrogenase complex. Biochem J:191-196. https://doi:10.1042/bj3290191

12. Westermaier T, Jauss A, Eriskat J, Kunze E, Roosen K (2009) Acute vasoconstriction: decrease and recovery of cerebral blood flow after various intensities of experimental subarachnoid hemorrhage in rats. J Neurosurg 110(5):996-1002. https://doi:10.3171/2008.8.JNS08591

13. Nygaard G, Di Paolo JA, Hammaker D, Boyle DL, Budas G, Notte GT, Mikaelian I, Barry V, Firestein GS (2018) Regulation and function of apoptosis signal-regulating kinase 1 in rheumatoid arthritis. Biochem Pharmacol 151:282-290. https://doi:10.1016/j.bcp.2018.01.041

14. Liu GJ, Tao T, Wang H, Zhou Y, Gao X, Gao YY, Hang CH, Li W (2020) Functions of resolvin D1ALX/FPR2 receptor interaction in the hemoglobin-induced microglial inflammatory response and neuronal injury. J Neuroinflammation 17(1):239. https://doi:10.1186/s12974-020-01918-x

15. Reed L (1981) Regulation of mammalian pyruvate dehydrogenase complex by a phosphorylationdephosphorylation cycle. Curr Top Cell Regul 18:95-106. https://doi:10.1016/b978-0-12-1528188.50012-8

16. Bock F, Tait S (2020) Mitochondria as multifaceted regulators of cell death. Nature reviews Molecular cell biology 21(2):85-100. https://doi:10.1038/s41580-019-0173-8

17. Woolbright BL, Rajendran G, Harris RA, Taylor JA 3rd (2019) Metabolic Flexibility in Cancer: Targeting the Pyruvate Dehydrogenase Kinase:Pyruvate Dehydrogenase Axis. Mol Cancer Ther 18(10):1673- 
1681. https://doi:10.1158/1535-7163.MCT-19-0079

18. Lu Y, Zhang XS, Zhou XM, Gao YY, Chen CL, Liu JP, Ye ZN, Zhang ZH, Wu LY, Li W, Hang CH (2019) Peroxiredoxin $1 / 2$ protects brain against $\mathrm{H} 2 \mathrm{O} 2$-induced apoptosis after subarachnoid hemorrhage. FASEB J 33(2):3051-3062. https://doi:10.1096/fj.201801150R

19. Schuette AJ, Barrow DL (2013) Epidemiology and long-term mortality in subarachnoid hemorrhage. World Neurosurg 80(3-4):264-265. https://doi:10.1016/j.wneu.2012.10.049

20. Tao T, Liu GJ, Shi X, Zhou Y, Lu Y, Gao YY, Zhang XS, Wang H, Wu LY, Chen CL, Zhuang Z, Li W, Hang CH (2019) DHEA Attenuates Microglial Activation via Induction of JMJD3 in Experimental Subarachnoid Haemorrhage. J Neuroinflammation 16(1):243. https://doi:10.1186/s12974-019-1641-y

21. Sehba FA, Hou J, Pluta RM, Zhang JH (2012) The importance of early brain injury after subarachnoid hemorrhage. Prog Neurobiol 97(1):14-37. https://doi:10.1016/j.pneurobio.2012.02.003

22. Kim J, Kim HY, Song SY, Go SH, Sohn HS, Baik S, Soh M, Kim K, Kim D, Kim HC, Lee N, Kim BS, Hyeon T (2019) Synergistic Oxygen Generation and Reactive Oxygen Species Scavenging by Manganese Ferrite/Ceria Co-decorated Nanoparticles for Rheumatoid Arthritis Treatment. ACS Nano 13(3):32063217. https://doi:10.1021/acsnano.8b08785

23. Peng F, Wang JH, Fan WJ, Meng YT, Li MM, Li TT, Cui B, Wang HF, Zhao Y, An F, Guo T, Liu XF, Zhang L, Lv L, Lv DK, Xu LZ, Xie JJ, Lin WX, Lam EW, Xu J, Liu Q (2018) Glycolysis gatekeeper PDK1 reprograms breast cancer stem cells under hypoxia. Oncogene 37(8):1119. https://doi:10.1038/onc.2017.407

24. Kilkenny C, Browne W, Cuthill IC, Emerson M, Altman DG, Group NCRRGW (2010) Animal research: reporting in vivo experiments: the ARRIVE guidelines. Br J Pharmacol 160(7):1577-1579. https://doi:10.1111/j.1476-5381.2010.00872.x

25. Lu B, Wang Z, Ding Y, Wang X, Lu S, Wang C, He C, Piao M, Chi G, Luo Y, Ge P (2018) RIP1 and RIP3 contribute to shikonin-induced glycolysis suppression in glioma cells via increase of intracellular hydrogen peroxide. Cancer Lett 425:31-42. https://doi:10.1016/j.canlet.2018.03.046

26. Liu GJ, Zhang QR, Gao X, Wang H, Tao T, Gao YY, Zhou Y, Chen XX, Li W, Hang CH (2020) MiR-146a Ameliorates Hemoglobin-Induced Microglial Inflammatory Response via TLR4/IRAK1/TRAF6 Associated Pathways. Front Neurosci 14:311. https://doi:10.3389/fnins.2020.00311

27. Nechushtan A, Smith C, Hsu Y, Youle R (1999) Conformation of the Bax C-terminus regulates subcellular location and cell death. EMBO J 18(9):2330-2341. https://doi:10.1093/emboj/18.9.2330

28. Matsumura K, Kumar TP, Guddanti T, Yan Y, Blackburn SL, McBride DW (2019) Neurobehavioral Deficits After Subarachnoid Hemorrhage in Mice: Sensitivity Analysis and Development of a New Composite Score. J Am Heart Assoc 8(8):e011699. https://doi:10.1161/JAHA.118.011699

29. Westermaier T, Jauss A, Eriskat J, Kunze E, Roosen K (2009) Time-course of cerebral perfusion and tissue oxygenation in the first $6 \mathrm{~h}$ after experimental subarachnoid hemorrhage in rats. $\mathrm{J}$ Cereb Blood Flow Metab 29(4):771-779. https://doi:10.1038/jcbfm.2008.169

30. Hayyan M, Hashim MA, AINashef IM (2016) Superoxide Ion: Generation and Chemical Implications. Chem Rev 116(5):3029-3085. https://doi:10.1021/acs.chemrev.5b00407

31. Devasagayam T, Tilak J, Boloor K, Sane K, Ghaskadbi S, Lele R (2004) Free radicals and antioxidants in human health: current status and future prospects. J Assoc Phys India 52:794-804 
32. Kinnaird A, Dromparis P, Saleme B, Gurtu V, Watson K, Paulin R, Zervopoulos S, Stenson T, Sutendra G, Pink DB, Carmine-Simmen K, Moore R, Lewis JD, Michelakis ED (2016) Metabolic Modulation of Clearcell Renal Cell Carcinoma with Dichloroacetate, an Inhibitor of Pyruvate Dehydrogenase Kinase. Eur Urol 69(4):734-744. https://doi:10.1016/j.eururo.2015.09.014

33. McFate T, Mohyeldin A, Lu H, Thakar J, Henriques J, Halim ND, Wu H, Schell MJ, Tsang TM, Teahan O, Zhou S, Califano JA, Jeoung NH, Harris RA, Verma A (2008) Pyruvate dehydrogenase complex activity controls metabolic and malignant phenotype in cancer cells. J Biol Chem 283(33):22700-22708. https://doi:10.1074/jbc.M801765200

34. Westermaier T, Jauss A, Eriskat J, Kunze E, Roosen K (2011) The temporal profile of cerebral blood flow and tissue metabolites indicates sustained metabolic depression after experimental subarachnoid hemorrhage in rats. Neurosurgery 68(1):223-229. https://doi:10.1227/NEU.0b013e3181fe23c1 discussion 229-230.

35. Hattori K, Naguro I, Runchel C, Ichijo H (2009) The roles of ASK family proteins in stress responses and diseases. Cell Commun Signal 7:9. https://doi:10.1186/1478-811X-7-9

36. Rao Y, Gammon S, Zacharias NM, Liu T, Salzillo T, Xi Y, Wang J, Bhattacharya P, Piwnica-Worms D (2020) Hyperpolarized [1-(13)C]pyruvate-to-[1-(13)C]lactate conversion is rate-limited by monocarboxylate transporter-1 in the plasma membrane. Proc Natl Acad Sci U S A 117(36):2237822389. https://doi:10.1073/pnas0.23537117

37. Cosgrove BD, Gilbert PM, Porpiglia E, Mourkioti F, Lee SP, Corbel SY, Llewellyn ME, Delp SL, Blau HM (2014) Rejuvenation of the muscle stem cell population restores strength to injured aged muscles. Nat Med 20(3):255-264. https://doi:10.1038/nm.3464

38. Zhang X, St Leger R, Fang W (2017) Pyruvate Accumulation Is the First Line of Cell Defense against Heat Stress in a Fungus. mBio 8 (5). https://doi:10.1128/mBio.01284-17

39. Anerillas C, Abdelmohsen K, Gorospe M (2020) Regulation of senescence traits by MAPKs. Geroscience 42(2):397-408. doi:10.1007/s11357-020-00183-3

40. McGrath JC, Lilley E (2015) Implementing guidelines on reporting research using animals (ARRIVE etc.): new requirements for publication in BJP. Br J Pharmacol 172(13):3189-3193. https://doi:10.1111/bph.12955

41. Alnemri E, Livingston D, Nicholson D, Salvesen G, Thornberry N, Wong W, Yuan J (1996) Human ICE/CED-3 protease nomenclature. Cell 87(2):171. https://doi:10.1016/s0092-8674(00)81334-3

42. Popov K, Kedishvili N, Zhao Y, Gudi R, Harris R (1994) Molecular cloning of the p45 subunit of pyruvate dehydrogenase kinase. J Biol Chem 269(47):29720-29724

43. Segales J, Perdiguero E, Munoz-Canoves P (2016) Regulation of Muscle Stem Cell Functions: A Focus on the p38 MAPK Signaling Pathway. Front Cell Dev Biol 4:91. https://doi:10.3389/fcell.2016.00091

44. Macdonald RL (2014) Delayed neurological deterioration after subarachnoid haemorrhage. Nat Rev Neurol 10(1):44-58. https://doi:10.1038/nrneurol.2013.246

45. Jennett B, Bond M (1975) Assessment of outcome after severe brain damage. Lancet 1(7905):480-484 https://doi:10.1016/s0140-6736(75)92830-5 


\section{Figures}

A Experiment 1: The cellular location and expression variation of PDK4 in rat brain after SAH

\begin{tabular}{|c|c|c|c|c|}
\hline SAH $<$ WB, qPCR & WB, qPCR & WB, qPCR, IF & WB, qPCR & $\underset{\mathrm{WB}, \mathrm{qPCR}}{\stackrel{\longrightarrow}{\longrightarrow}}$ \\
\hline $6 \mathrm{~h}$ & $24 \mathrm{~h}$ & 20 & $3 d$ & $7 d$ \\
\hline
\end{tabular}

B Experiment 2: The expression variation of PDK4 and PDH in neurons after $\mathrm{Hb}$ stimulation

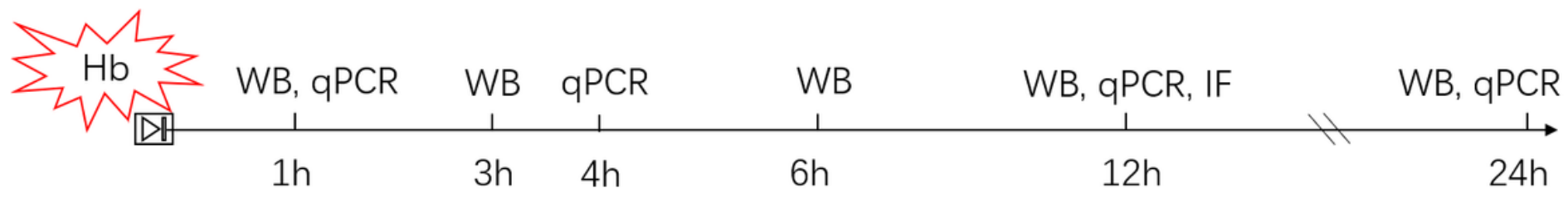

C Experiment 3: The levels of PDK4 and pyruvate in patients' CSF after SAH

ELISA

\section{Figure 1}

The experimental designs and groups. The experimental designs in vivo (A), in vitro (B) and in SAH patients' CSF (C). WB western blotting, qPCR quantitative real-time polymerase chain reaction, IF immunofluorescence staining, h hours, d days, SAH subarachnoid hemorrhage, Hb hemoglobin, CSF cerebrospinal fluid. 
A
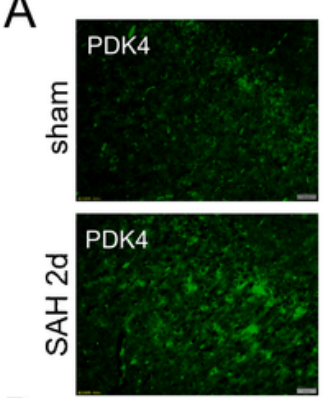

B
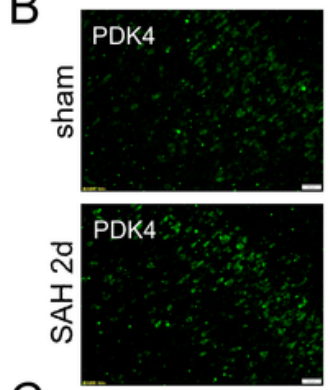

C
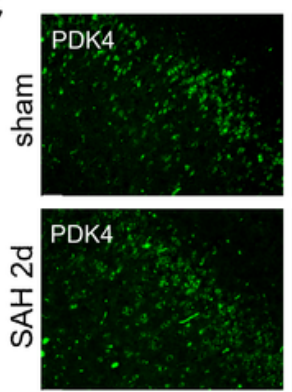

$\mathrm{F}$

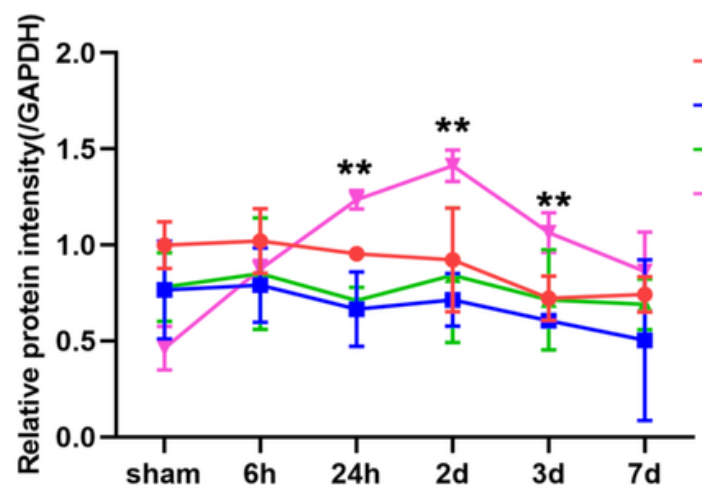

$\mathrm{D}$
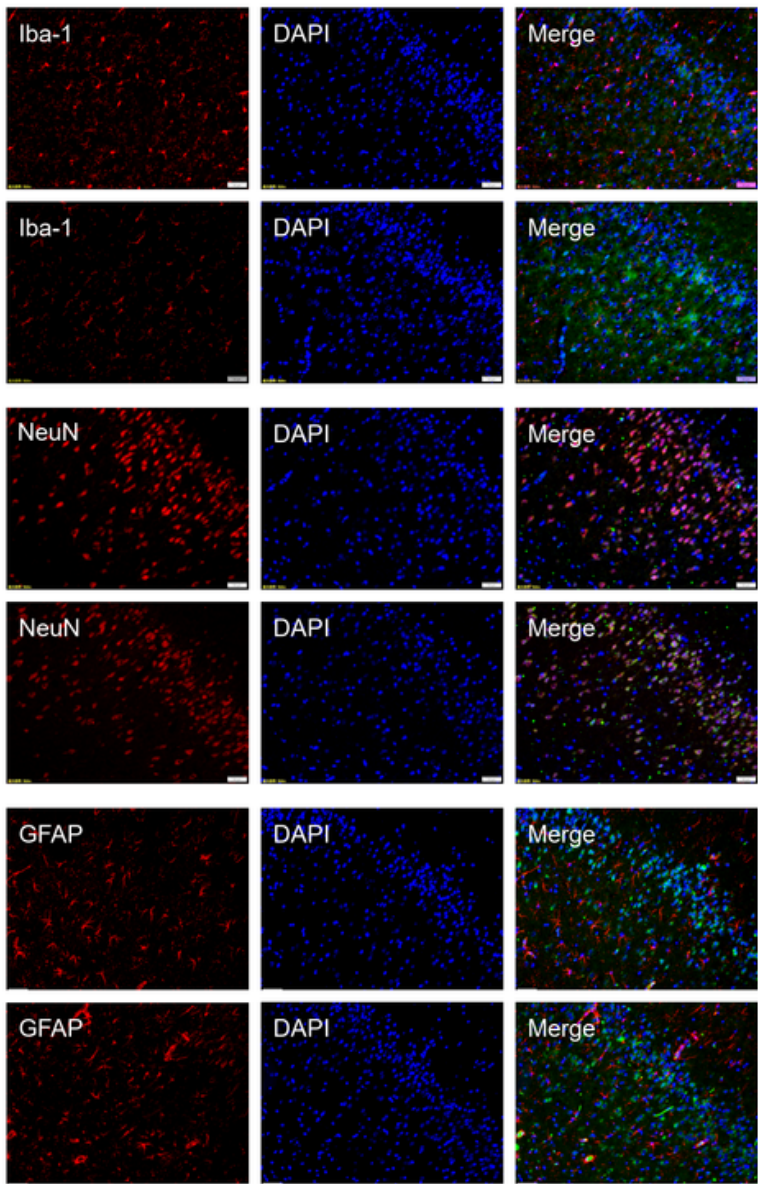

G

$\mathrm{E}$
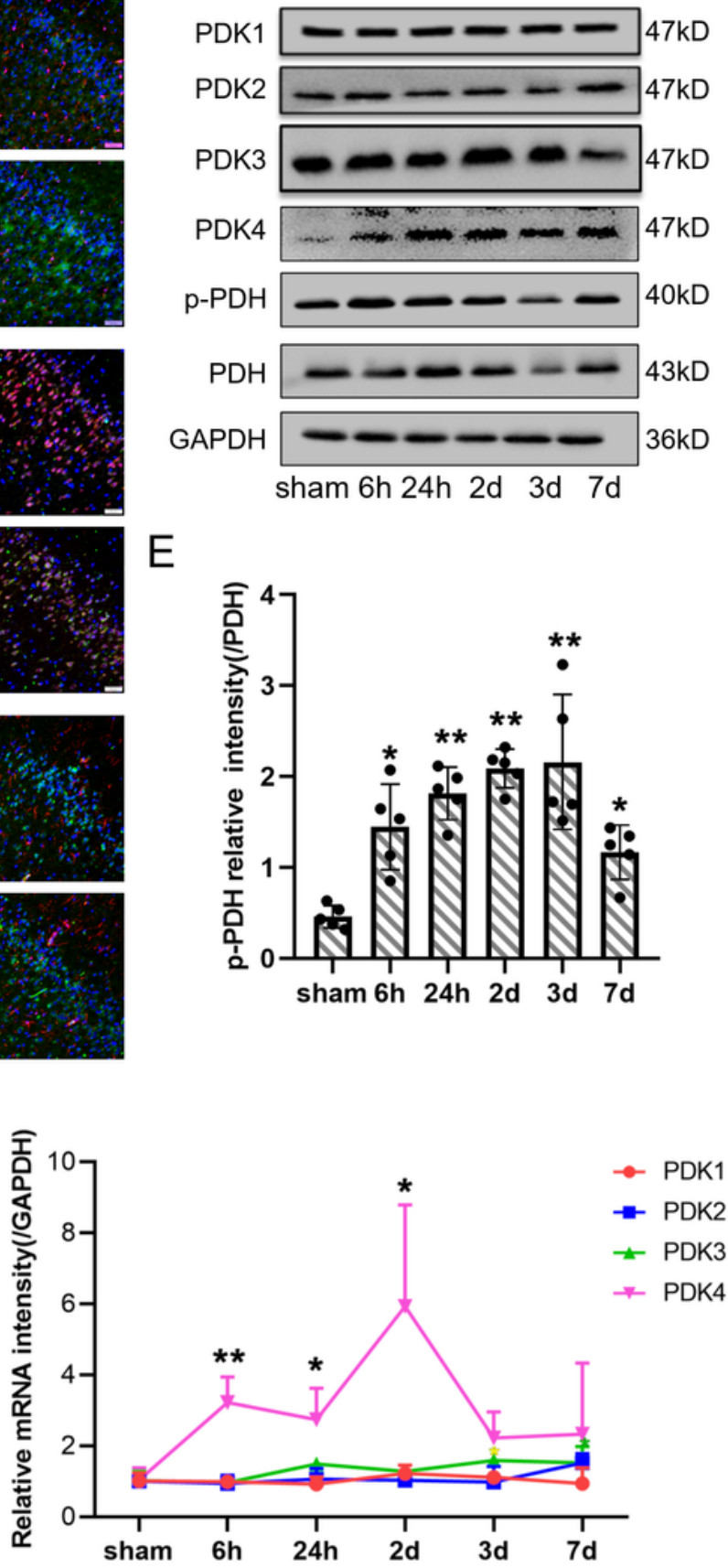

Figure 2

The expression and cellular distribution of PDKs in rat brains after SAH. Representative immunofluorescence staining of PDK4, Iba1 (a microglial marker) (A), NeuN (a neuronal marker) (B), and GFAP (an astrocytic marker) (C) in the cortex of the right temporal lobe after SAH (PDK4 = green; NeuN, Iba1 and GFAP = red; and DAPI = blue). D) Representative bands of PDK1, PDK2, PDK3, PDK4, PDH and p-PDH expression in the cortex at each time point (0,6 and 24h and 2, 3 and $7 \mathrm{~d})$ after SAH. E) Quantitative analysis of Western blot results showed that the ratio of p-PDH/PDH was significantly increased after SAH. 
F, G) Quantitative analysis of western blot and qPCR results showed that variation of PDKs protein and mRNA levels after $S A H$. Bars represent the means $\pm S D$. ${ }^{*} P<0.05,{ }^{*} \mathrm{P}<0.01$, vs. sham ( $n=5$ in each group). Bar= 50 um.

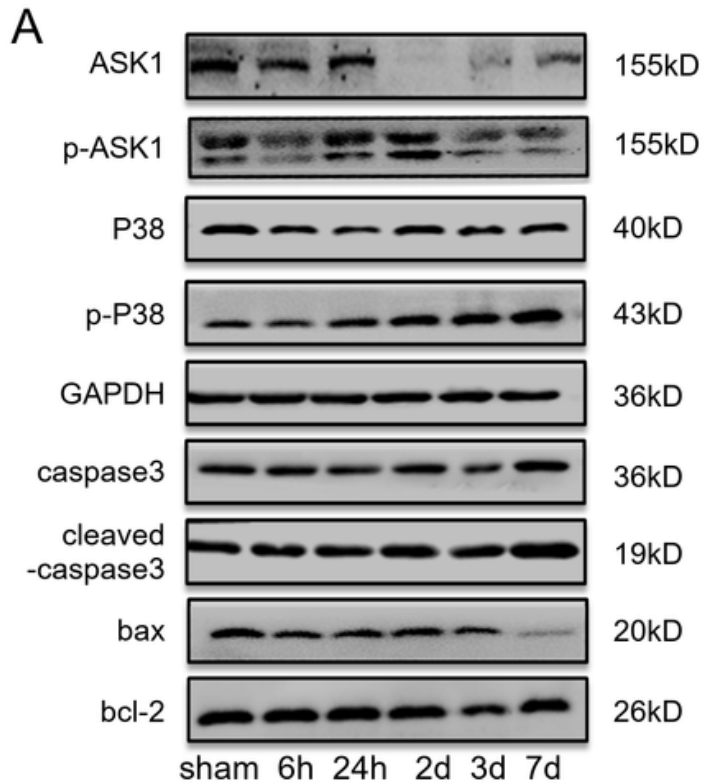

B

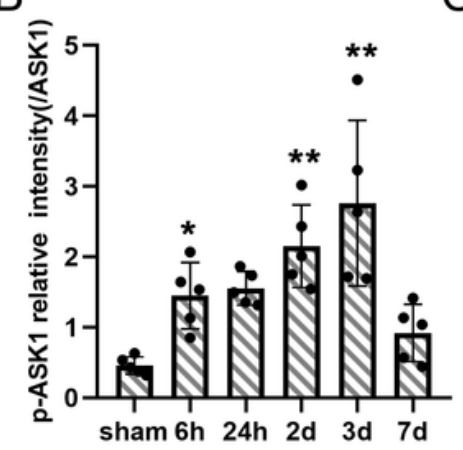

$\mathrm{C}$
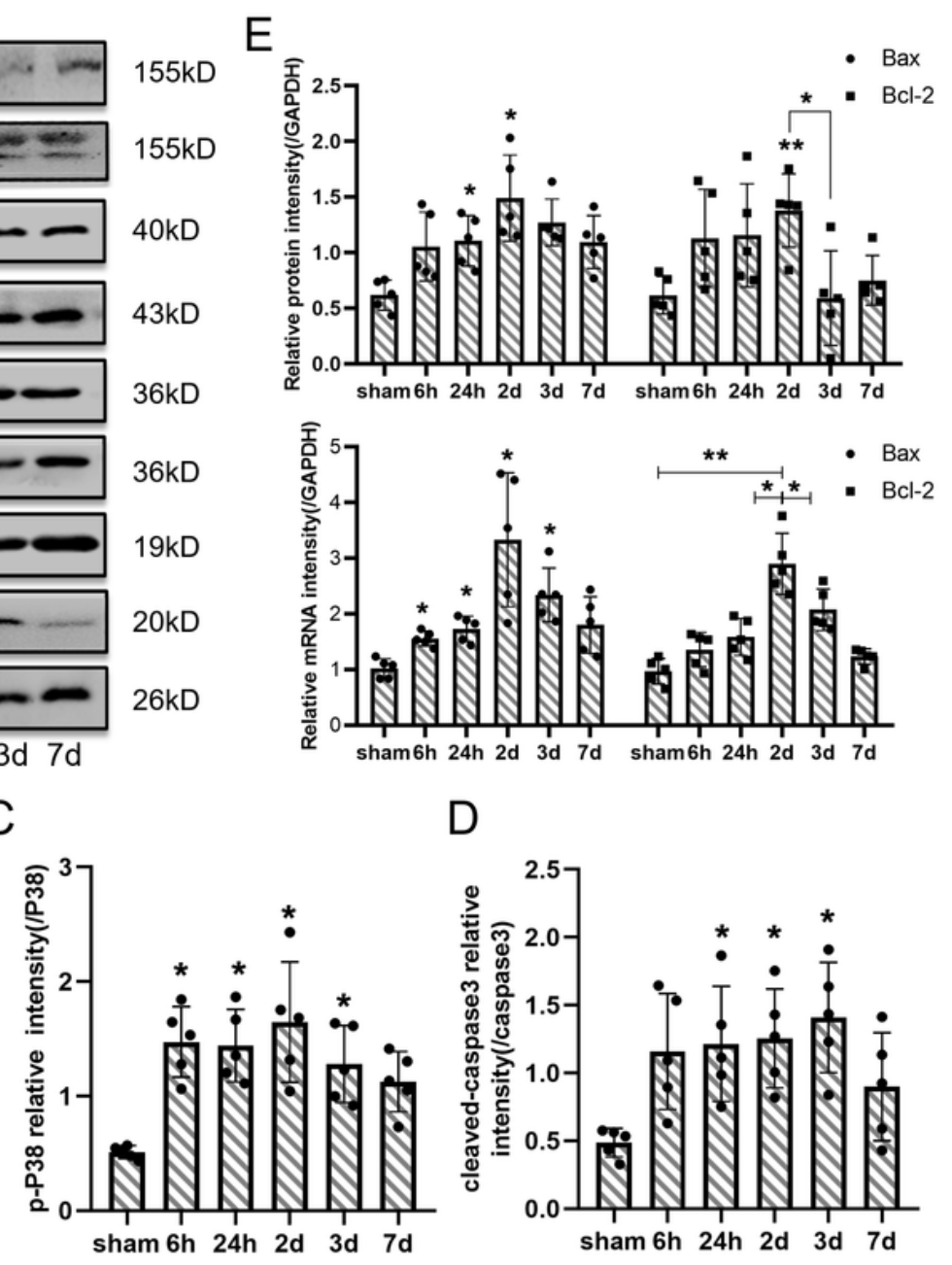

$\mathrm{F}$
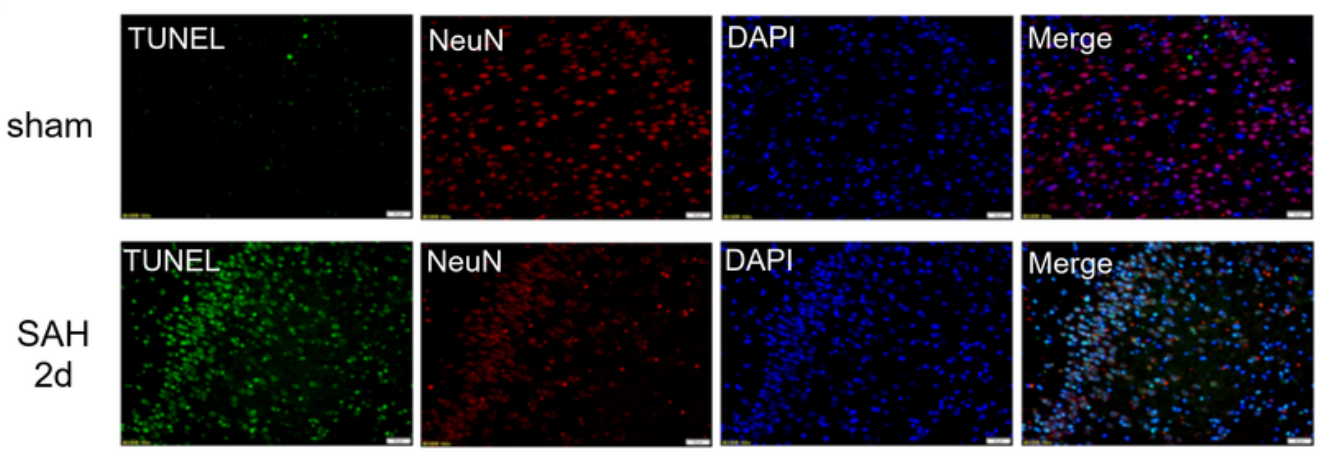

\section{Figure 3}

The apoptosis pathway was activated after SAH. A) Representative bands of ASK1, p-ASK1, P38, p-P38, caspase3, cleaved-caspase3, Bax and Bcl-2 expression in the cortex at each time point after SAH. B-D) Quantitative analysis of western blot results showed that the ratio of p-ASK1/ASK1, p-P38/P38 and cleaved- 
caspase3/caspase3 were signficantly increased after SAH. E) Quantitative analysis of western blot and qPCR results showed that the protein and mRNA levels of Bax and Bcl-2 were increased after SAH. F) Representative TUNEL staining in the cortex of right temporal lobe after SAH (TUNEL = green, NeuN = red, $\mathrm{DAPI}=$ blue $)$. Bars represent the means $\pm S D .{ }^{*} \mathrm{P}<0.05,{ }^{*} \mathrm{P}<0.01$, vs. sham $(\mathrm{n}=5$ in each group). Bar $=50$ um.
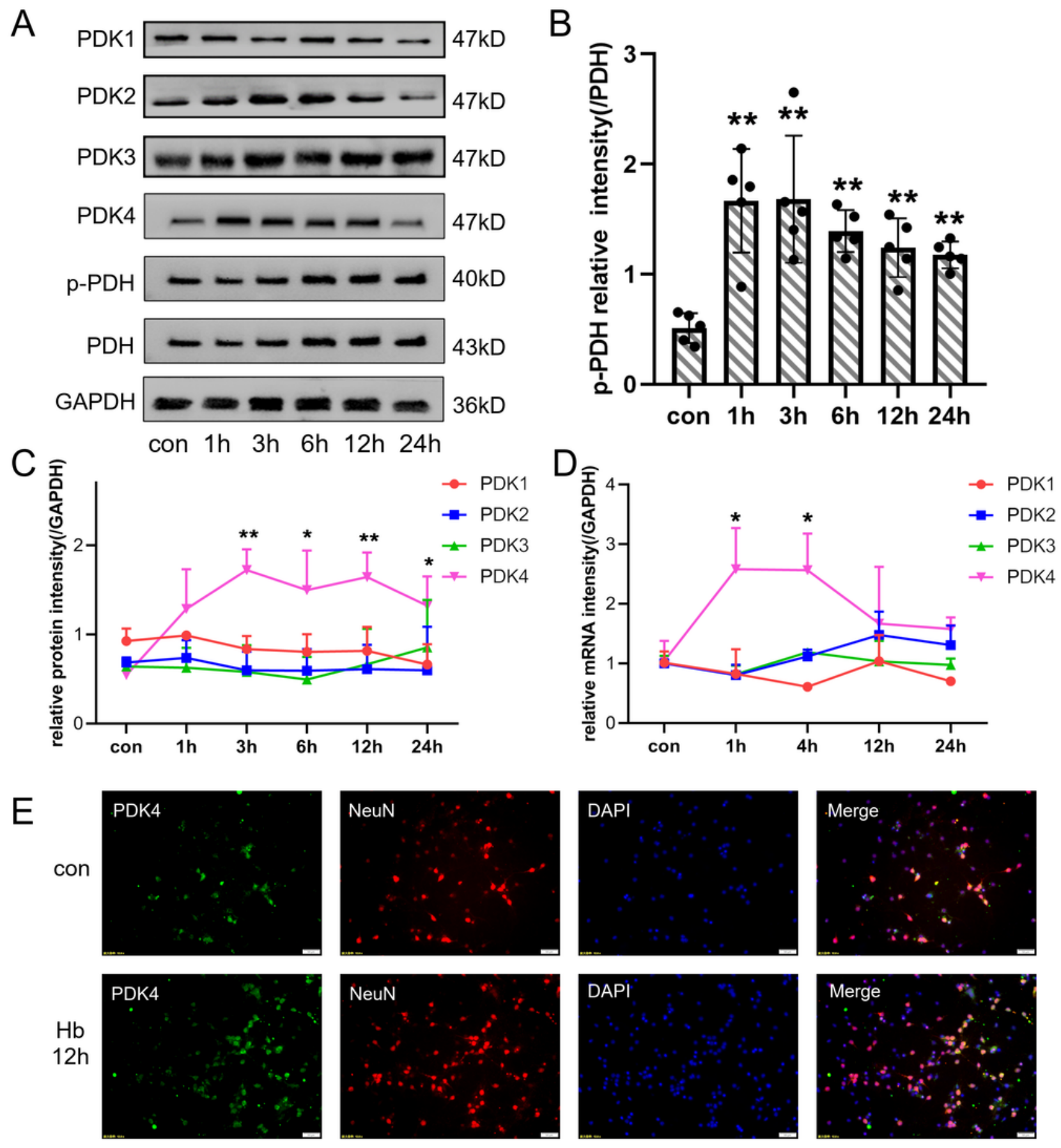

Figure 4 
The expression of PDKs in cultured primary neurons after $\mathrm{Hb}$ stimulation. A) Representative bands of PDK1, PDK2, PDK3, PDK4, PDH and p-PDH expression at each time point $(0,1,3,6,12$ and $24 \mathrm{~h})$ after $\mathrm{Hb}$ stimulation. B) Quantitative analysis of Western blot results showed that the ratio of $\mathrm{p}-\mathrm{PDH} / \mathrm{PDH}$ was significantly increased after $\mathrm{Hb}$ stimulation. C, D) Quantitative analysis of western blot and qPCR results showed that variation of PDKs protein at each time point $(0,1,3,6,12$ and $24 \mathrm{~h})$ and mRNA at each time point $(0,1,4,12$ and $24 \mathrm{~h})$ levels after $\mathrm{Hb}$ stimulation. E) Representative immunofluorescence staining for PDK4 and NeuN (a neuronal marker) in cultured primary neurons after $\mathrm{Hb}$ stimulation (PDK4 = green, NeuN $=$ red, $D A P I=$ blue). Bars represent the means $\pm S D . * P<0.05$, ${ }^{*} P<0.01$ vs. con ( $n=5$ in each group). Bar $=$ 50 um. 

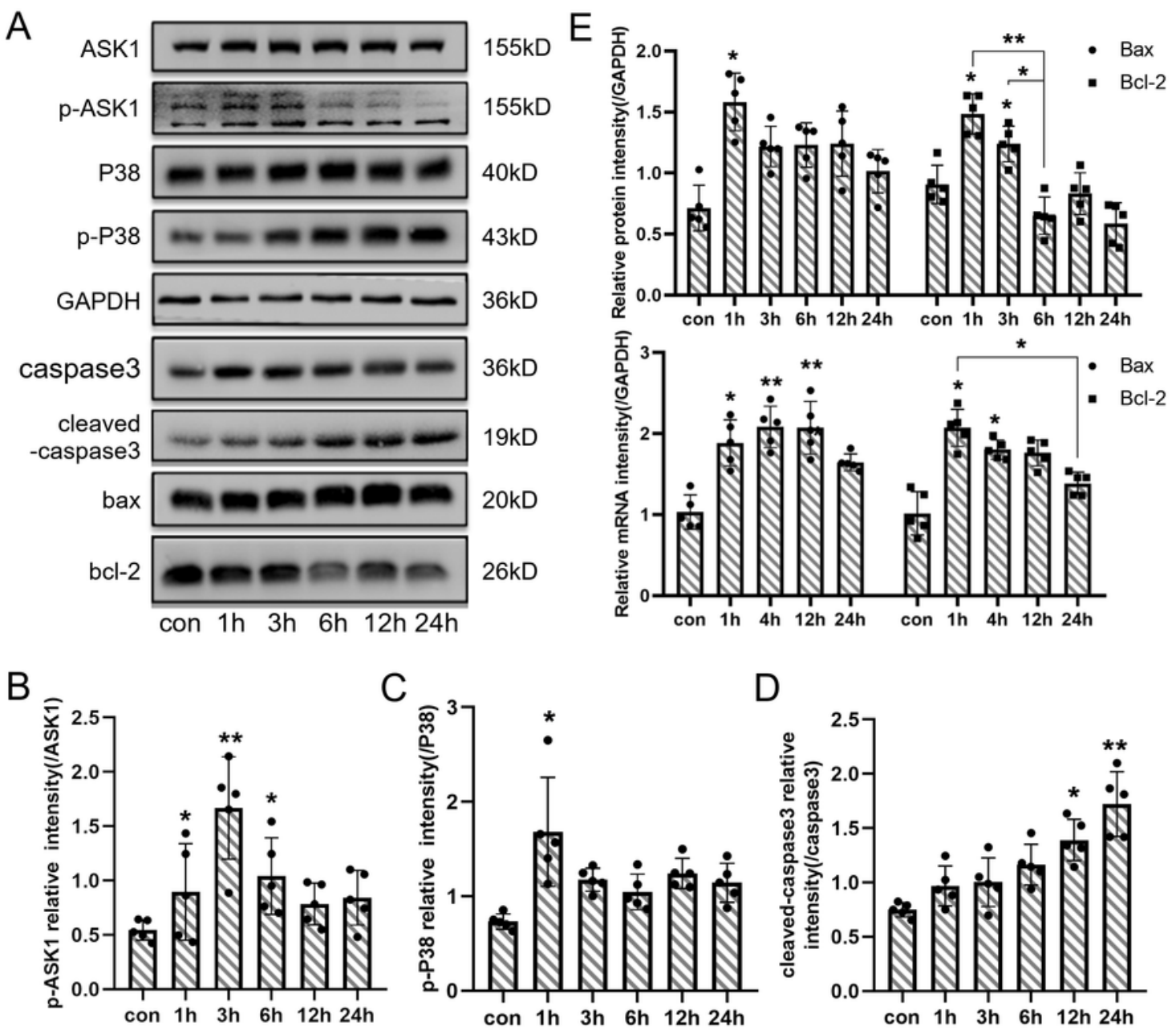

$\mathrm{F}$
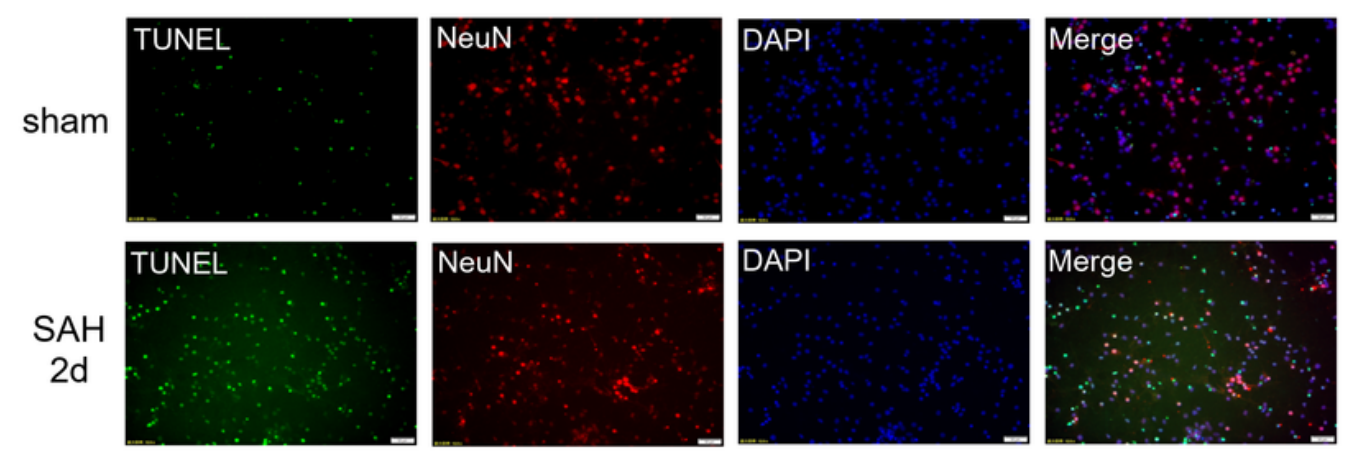

\section{Figure 5}

The neuronal apoptosis pathway was activated after $\mathrm{Hb}$ stimulation. A) Representative bands of ASK1, pASK1, P38, p-P38, caspase3, cleaved-caspase3, Bax and Bcl-2 expression in cultured primary neurons at each time point after $\mathrm{Hb}$ stimulation. B-D) Quantitative analysis of western blot results showed that the ratio of p-ASK1/ASK1, p-P38/P38 and cleaved-caspase3/caspase3 were significantly increased after $\mathrm{Hb}$ stimulation. E) Quantitative analysis of western blot and qPCR results showed that the protein and mRNA levels of Bax and Bcl-2 were increased after $\mathrm{Hb}$ stimulation. F) Representative TUNEL staining in cultured 
primary neurons after $\mathrm{Hb}$ stimulation $(T U N E L=$ green, $\mathrm{NeuN}=$ red, DAPI = blue). Bars represent the means \pm SD. ${ }^{*} P<0.05,{ }^{\star} \mathrm{P}<0.01$ vs. con ( $n=5$ in each group). Bar $=50$ um.
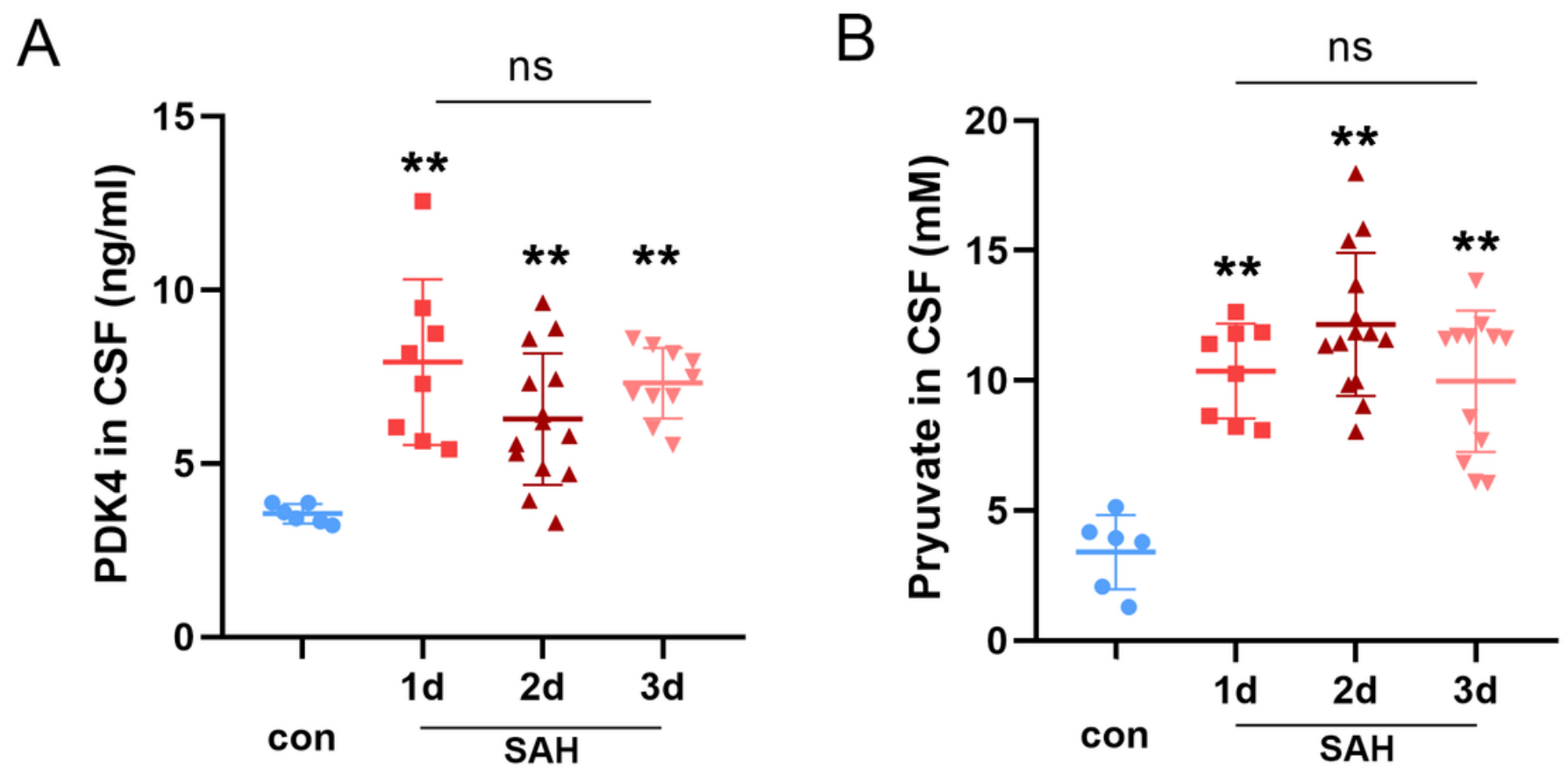

\section{Figure 6}

Scatter plots of the levels of PDK4 and pyruvate in controls and patients with SAH. Quantitative analysis of ELISA results showed that the levels of PDK4 (A) and pyruvate (B) were obviously increased in the CSF of patients 1-3 days after SAH compared with controls. Bars represent the means \pm SD. $* * P<0.01$ vs. con ( $n=6$ in the con group; $n=8,14$ and 10 in the groups on days 1,2 and 3 after $S A H$, respectively). 

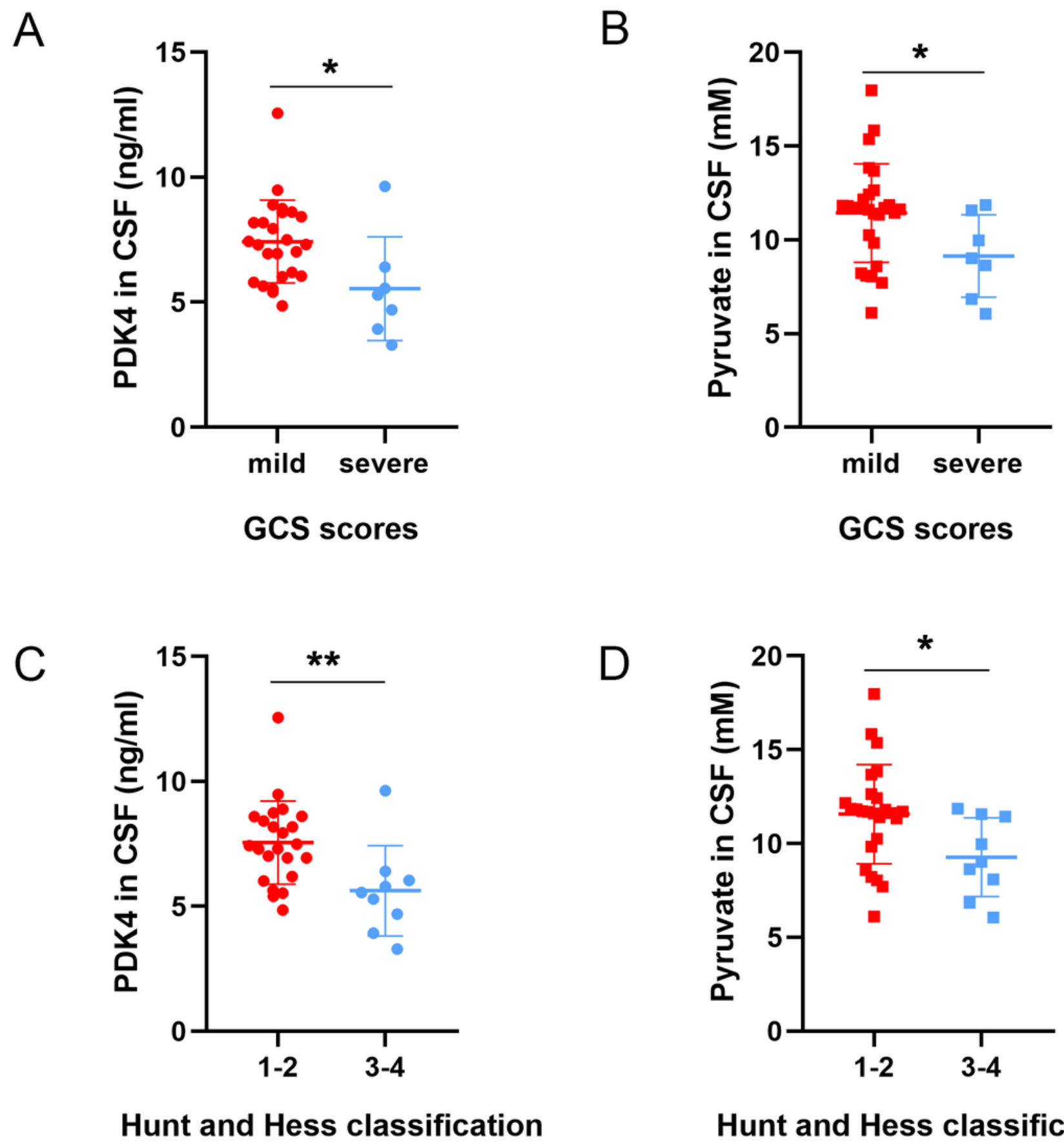

Hunt and Hess classification

Figure 7

Scatter plots of the levels of PDK4 and pyruvate sorted by injury category. Unpaired two-tailed t-tests indicated that higher expression of PDK4 and pyruvate was significantly associated with mild neurological injury 1-3 days after $\mathrm{SAH}(\mathrm{A}-\mathrm{D})$. Bars represent the means $\pm \mathrm{SD}$. ${ }^{*} \mathrm{P}<0.05$, ${ }^{*} \mathrm{P}<0.01 \mathrm{vs}$. the indicated groups $(n=7$ in the severe injury group (GCS score $<12), n=25$ in the mild injury group (GCS score 12-15), $n=9$ in the Hunt-Hess 3-4 group and $n=23$ in the Hunt-Hess 1-2 group) 

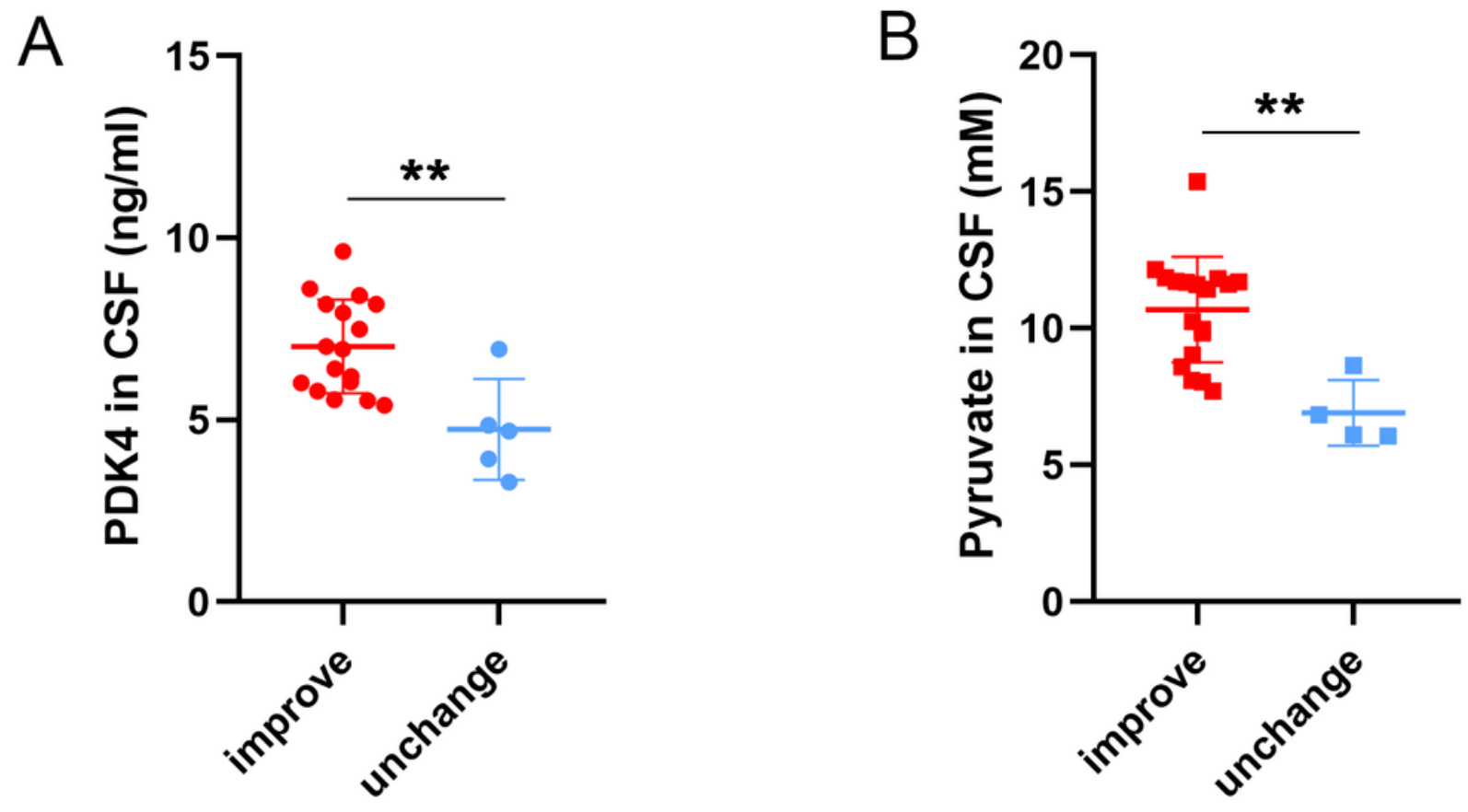

\section{Figure 8}

Scatter plots of the levels of PDK4 and pyruvate sorted by outcome category. Unpaired two-tailed t-tests indicated that higher expression of PDK4 and pyruvate was significantly associated with an improved outcome 3 months after SAH $(A, B)$. Bars represent the means $\pm S D$. ${ }^{*} P<0.05, * * P<0.01$ vs. the indicated groups ( $n=5$ in the unchanged group and $n=17$ in the improved group). 